\title{
Chapter 10 \\ Radiocesium Contamination of Marine Fish Muscle and Its Effective Elimination
}

\author{
Shugo Watabe, Hideki Ushio, and Daisuke Ikeda
}

\begin{abstract}
High concentrations of radiocesium $\left({ }^{134} \mathrm{Cs},{ }^{136} \mathrm{Cs}\right.$, and ${ }^{137} \mathrm{Cs}$ combined) were detected in several fish species such as nibe croaker, Pacific cod, and brown hakeling, which were collected from the Pacific Ocean off the coast of the Fukushima and Ibaraki Prefectures. High levels of radiocesium accumulated in fish muscle, but the radioactivity levels of naturally occurring radioactive $\mathrm{K}$ in some contaminated fish exceeded the levels of ${ }^{134} \mathrm{Cs}$ and ${ }^{137} \mathrm{Cs}$. Three washes with $0.1 \% \mathrm{NaCl}$ solution effectively removed the radiocesium from contaminated fish meat. This can be applied in the production of surimi-based products and other processed seafood such as boiled, dried, or seasoned products.
\end{abstract}

Keywords Fish $\bullet$ Muscle $\bullet$ Radioisotope $\bullet$ Surimi-based products $\bullet$ Washing

\footnotetext{
S. Watabe $(\triangle)$

Laboratory of Marine Biochemistry, Graduate School of Agricultural and Life Sciences, The University of Tokyo, Bunkyo, Tokyo 113-8657, Japan

Department of Marine Biochemistry, Kitasato University School of Marine Biosciences, Minami, Sagamihara, Kanagawa 252-0373, Japan

e-mail: swatabe@kitasato-u.ac.jp

H. Ushio

Laboratory of Marine Biochemistry, Graduate School of Agricultural and Life Sciences, The University of Tokyo, Bunkyo, Tokyo 113-8657, Japan

D. Ikeda

Department of Marine Biochemistry, Kitasato University School of Marine Biosciences, Minami, Sagamihara, Kanagawa 252-0373, Japan
} 


\subsection{Introduction}

The Fukushima nuclear disaster spread radiation across northern Japan in March 2011. Soon after the meltdown at the Fukushima Daiichi nuclear power plants owned by the Tokyo Electric Power Company, the government evacuated people who lived within $30 \mathrm{~km}$ of the plants. The building exploded on 15 March, apparently fueled by hydrogen. The fallout of radioactive materials spread to land, rivers, and ocean. In addition, over 500 tons of wastewater containing radioactive material was discharged into the Pacific Ocean. Radioactivity was detected in fish caught in the coastal areas near Fukushima Daiichi. Higher concentrations of radiocesium $\left({ }^{134} \mathrm{Cs}\right.$ and ${ }^{137} \mathrm{Cs}$ combined) were detected in plaice (Paralichthys olivaceus) caught in August (58-590 Bq/kg) compared with in April (approximately $82 \mathrm{~Bq} / \mathrm{kg}$ ) in Fukushima Prefecture (Fishery Research Agency 2012). Thus, the government declared that fisheries products intended for sale should not contain a level exceeding $500 \mathrm{~Bq} / \mathrm{kg}$ at the market in Japan, which had not been the case since 1940 after World War II. Certain fish were found to contain radiocesium at levels of $>500 \mathrm{~Bq} /$ $\mathrm{kg}$, such as plaice and sea bass (Lateolabrax japonicus). Recently, the government decided to reduce the limit for radiocesium in fish sold in the market to $<100 \mathrm{~Bq} / \mathrm{kg}$. This limit is extremely safe for consumption, but it has been very difficult for fisheries and related industries to operate in the coastal areas near Fukushima Daiichi because many fish are contaminated with radiocesium above this level. Therefore, it would be desirable to have methods that reduce the concentration of radiocesium in fish so that people engaged in fisheries and related industries can resume their activities and earn a living. Our study aimed to determine the effects of washing fish to remove radiocesium contamination from the muscles that can be then used to manufacture surimi-based products, which are some of the most popular and traditional forms of seafood consumed in Japan.

\subsection{Detection of the Tissue Distribution of Radioactive Materials in Fish Using an Imaging Plate System}

Pacific cod (Gadus macrocephalus), bonefish (Pterothrissus gissu), white croaker (Pennahia argentata), and nibe croaker (Nibea albiflora) were collected at depths of 14-180 $\mathrm{m}$ in the Pacific Ocean off Fukushima on August 11th and September 11th, 2011, and subjected to tissue distribution analysis using an imaging plate (IP) system (Watabe et al. 2013). The IP system was used for two-dimensional radioactivity monitoring. Various tissues were dissected from fish samples, which were placed on an IP (BAS-MS2025IP, Fuji film Co. Ltd.) and stored at $-30^{\circ} \mathrm{C}$ for 2 weeks. Subsequently, IP was scanned using an image analyzer (FLA-5000, Fujifilm Co. Ltd., Tokyo, Japan) to detect radioactive tissues. White croaker caught in the East China Sea was used as the negative control in the IP system.

Relatively high signals were detected in the muscle, backbone (vertebral bones with neural and hemal spine bones), skin, and fins of Pacific cod (body weight $=744 \mathrm{~g}$ 

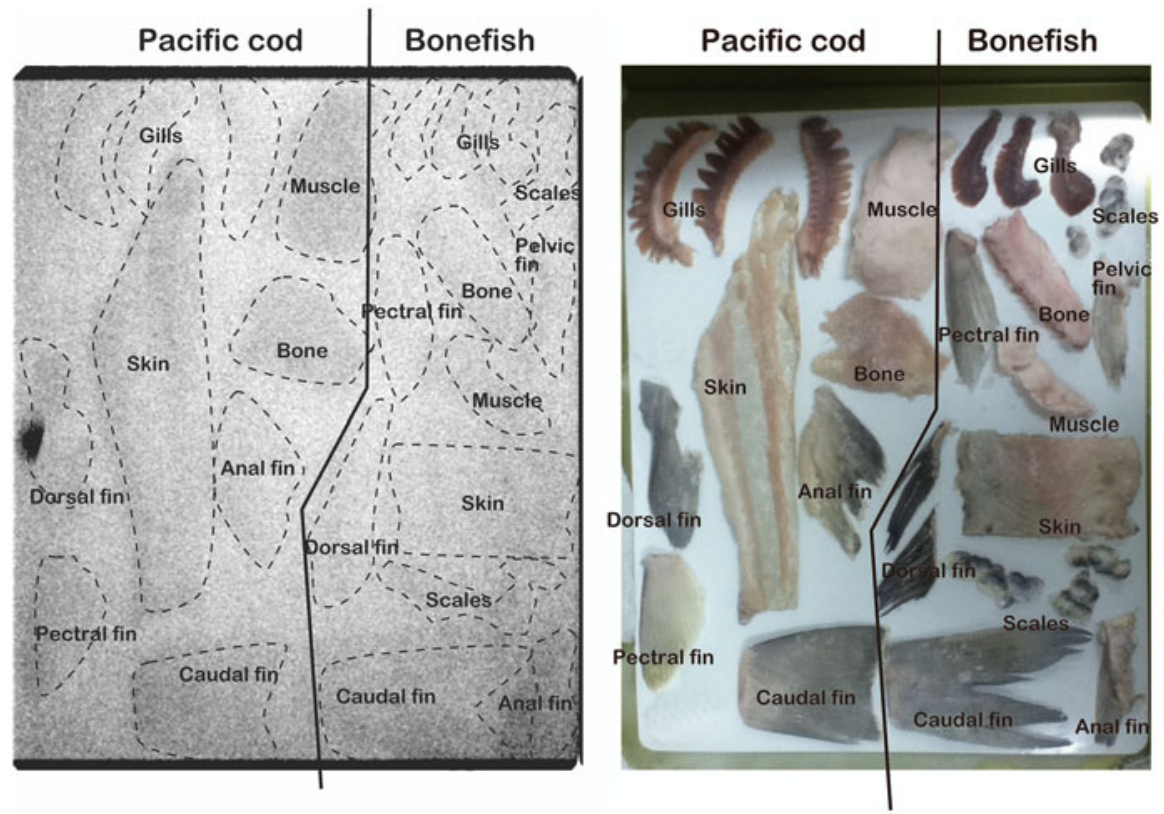

Fig. 10.1 Image plate analysis of various tissues from Pacific cod and bonefish (Watabe et al. 2013)

and total cesium radioactivity $=152 \mathrm{~Bq} / \mathrm{kg}$; Fig. 10.1). The signal distribution in the backbone and skin indicated that the positive signals in these areas were attributable to the attached muscle tissues. No obvious signal was detected in bonefish (body weight $=685 \mathrm{~g}$ and total $\mathrm{Cs}$ radioactivity $=17 \mathrm{~Bq} / \mathrm{kg}$ ). Radioactive substances were also detected in the muscle and fins of nibe croaker (body weight $=368 \mathrm{~g}$ and total cesium radioactivity $=515 \mathrm{~Bq} / \mathrm{kg}$; Fig. 10.2).

The Daigo Fukuryu Maru (fishing vessel) operating near Bikini Atoll in 1954 was affected by the nuclear fallout from a US hydrogen bomb test. Saiki et al. (1955) analyzed dorado (Coryphaena hippurus) caught in the Pacific Ocean and detected high radioactivity levels in the liver, kidney, spleen, and pyloric appendage and relatively high levels in the skin and gills.

It is important to note that the uncontaminated white croaker captured in the East China Sea also produced positive signals in similar tissues, which almost exceeded the signal intensity detected in the contaminated white croaker (total radioactivity of $\mathrm{Cs}=55 \mathrm{~Bq} / \mathrm{kg}$ ) captured near Fukushima (Fig. 10.3; Watabe et al. 2013).

A disadvantage of the IP system is that it detects all radiations, which can only be ascribed to specific radionuclides if they are known to be present. Thus, a germanium semiconductor detector (SGD-GEM-5030P4, Ortec, Seiko EG\&G Co. Ltd., Tokyo, Japan) was used to detect the radioactivity levels of ${ }^{134} \mathrm{Cs}$ and ${ }^{137} \mathrm{Cs}$, which showed that the naturally occurring ${ }^{40} \mathrm{~K}$ was present in addition to signals produced by ${ }^{134} \mathrm{Cs}$ and ${ }^{137} \mathrm{Cs}$ (Fig. 10.4; Watabe et al. 2013). Similarly high 

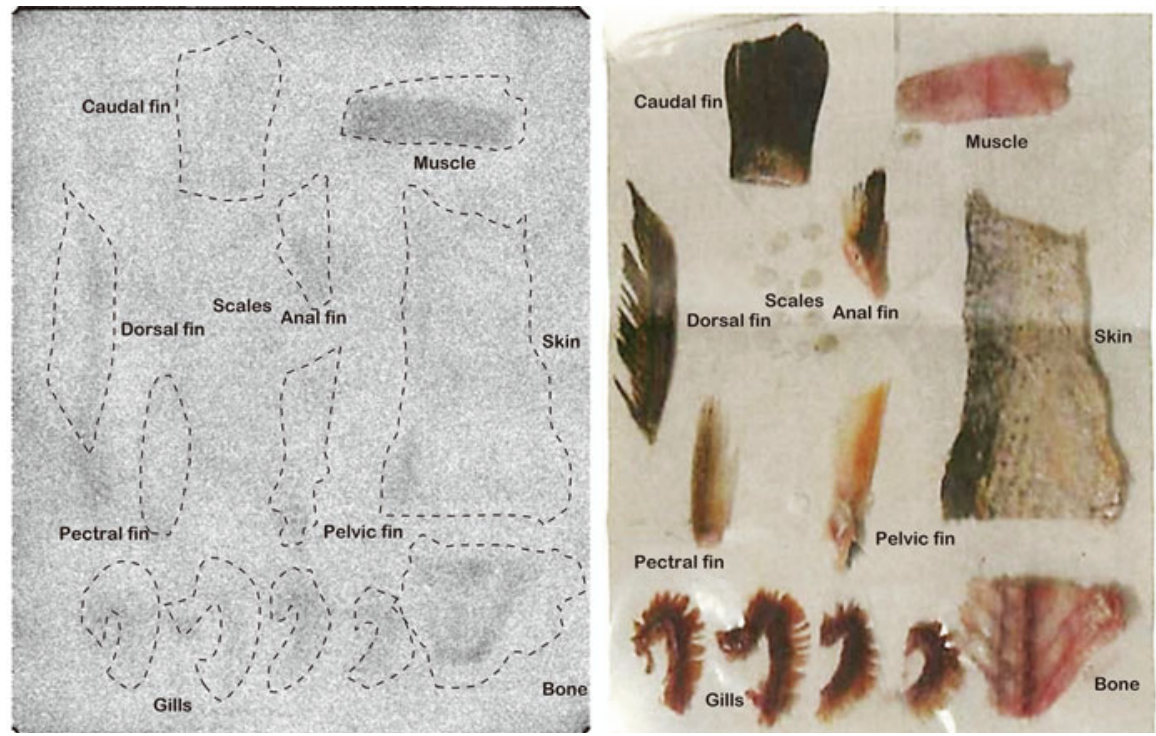

Fig. 10.2 Image plate analysis of various tissues from nibe croaker (Watabe et al. 2013)

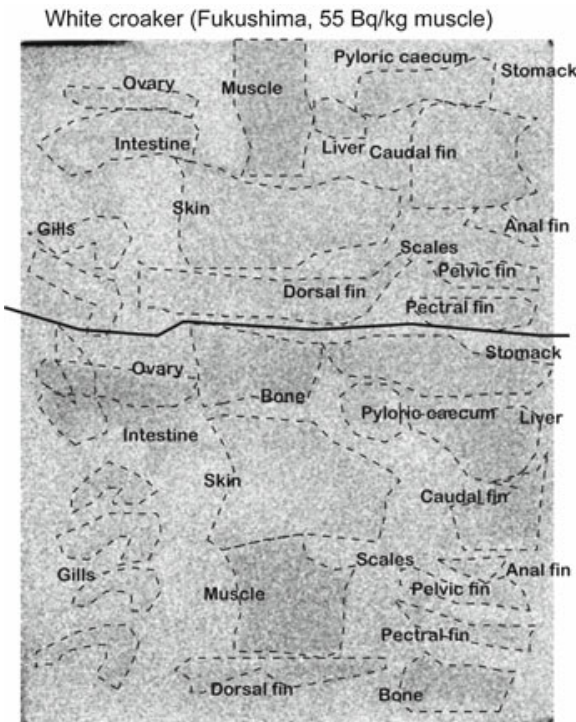

White croaker (East China Sea, not detected)
White croaker (Fukushima, 55 Bq/kg muscle)

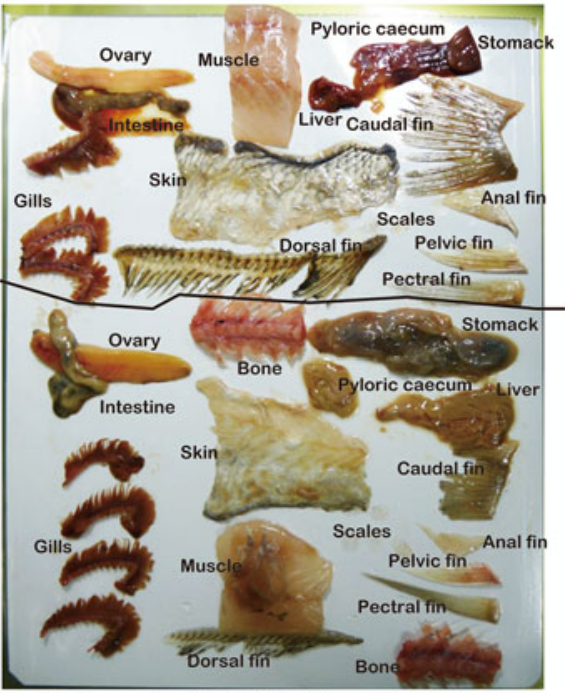

White croaker (East China Sea, not detected)

Fig. 10.3 Image plate analysis of various tissues from white croaker contaminated with radioactive materials and those from uncontaminated fish (Watabe et al. 2013) 


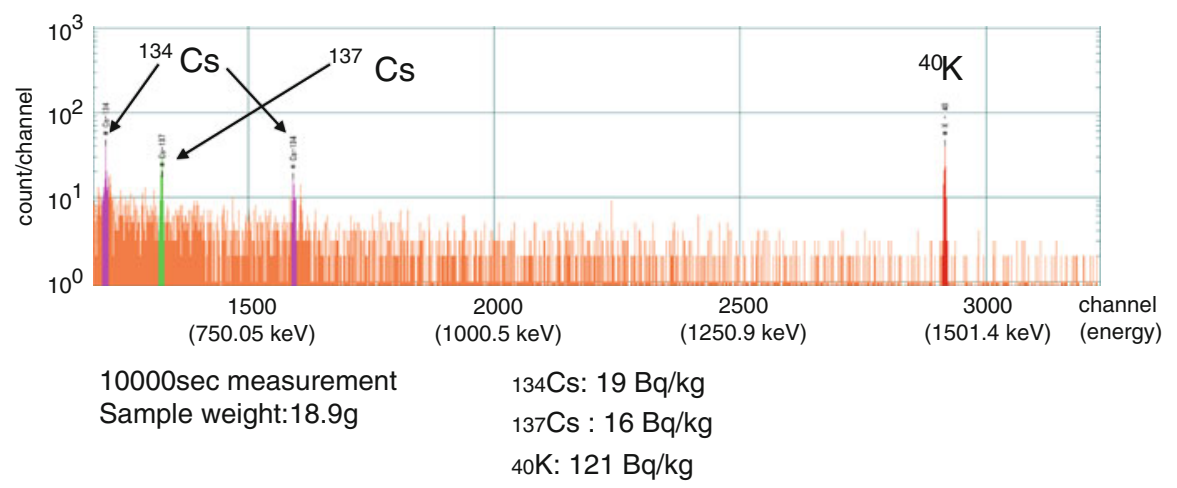

Fig. 10.4 Measurement of radionuclide contamination of Pacific cod muscle (685 g) using a germanium semiconductor detector (Watabe et al. 2013)

concentrations of ${ }^{40} \mathrm{~K}$ compared with those of ${ }^{134} \mathrm{Cs}$ and ${ }^{137} \mathrm{Cs}$ have also been reported for Pacific bluefin tuna (Thunnus orientalis), where the latter concentrations were trivial (Madigan et al. 2012). The $\mathrm{K}$ ion is accumulated at high levels in the intracellular spaces of animals and plants, so radioactive ${ }^{40} \mathrm{~K}$ is often present in the organ which is rich in live cells. Thus, the IP system and radiation detectors without spectroscopy may overestimate the radioactivity levels attributable to radiocesium in cell-rich food materials.

\subsection{Effective Elimination of Radiocesium Contamination from Fish Meat}

We tested the effects of washing fish muscle on removal of radiocesium contamination (Watabe et al. 2013).

In order to determine the most efficient washing method for removing radioactive cesium from fish meat, we determined the effects of different volumes of washing solutions on the residual cesium radioactivity in fish meat. The surimi production process often includes washing steps that use relatively low concentrations of salt solution; therefore, washing procedures using $0.1 \% \mathrm{NaCl}$ solution were employed in our study. The ordinary muscle of nibe croaker (body weight $=241-368 \mathrm{~g}$ and body length $=27.8-30.0 \mathrm{~cm}$ ) was cut into small pieces and added to various volumes of $0.1 \%(\mathrm{w} / \mathrm{v}) \mathrm{NaCl}$ solution (Watabe et al. 2013). The muscle pieces were stirred in the salt solution at $15^{\circ} \mathrm{C}$ for $5 \mathrm{~min}$. After centrifugation at 2,500×g for $10 \mathrm{~min}$, the pellets were subjected to further washing procedures in $0.1 \% \mathrm{NaCl}$ solution under the same conditions. The residual levels of radioactive cesium (approximately $1 / 3 \mathrm{rd}$ of the original level) reached a plateau after being washed with three volumes of wash solution (Table 10.1), which suggested that three volumes of wash solution is adequate for the removal of cesium from nibe meat. Saiki et al. (1955) also reported that washing the meat of yellowfin tuna (Thunnus albacores) in an equal volume of 
Table 10.1 Effects of washing volumes on the residual radiocesium level in nibe muscle (cited from Watabe et al. 2013)

\begin{tabular}{lllll}
\hline Volume & ${ }^{134} \mathrm{Cs}(\mathrm{Bq} / \mathrm{kg})$ & ${ }^{137} \mathrm{Cs}(\mathrm{Bq} / \mathrm{kg})$ & Total Cs $(\mathrm{Bq} / \mathrm{kg})$ & Residual Cs $(\%)$ \\
\hline Meat & 93.7 & 127 & 220.7 & 100 \\
3 & 38.3 & 47.2 & 85.5 & 38.8 \\
4 & 29.8 & 41.6 & 71.4 & 32.2 \\
5 & 37.8 & 46.7 & 84.5 & 38.5 \\
9 & 25.8 & 36 & 61.8 & 31.6 \\
\hline
\end{tabular}

Table 10.2 Effects of washing times on the residual radiocesium level in Pacific cod muscle (cited from Watabe et al. 2013)

\begin{tabular}{lllll}
\hline Washing & ${ }^{134} \mathrm{Cs}(\mathrm{Bq} / \mathrm{kg})$ & ${ }^{137} \mathrm{Cs}(\mathrm{Bq} / \mathrm{kg})$ & Total Cs $(\mathrm{Bq} / \mathrm{kg})$ & Residual Cs $(\%)$ \\
\hline 0 & - & - & 163 & 100 \\
1 & 29.5 & 35.7 & 65.2 & 40.3 \\
1 & 26.3 & 39.9 & 66.2 & 41 \\
1 & 37.8 & 46.7 & 84.5 & 38.5 \\
1 average & & & & 41.5 \\
2 & 24.2 & 24.3 & 48.5 & 30 \\
2 & 20.7 & $23.2^{\mathrm{a}}$ & 43.9 & 27.1 \\
2 average & & & & 28.6 \\
3 & 13.9 & 23.5 & 37.4 & 23.1 \\
3 & 15.1 & 21.3 & 36.4 & 22.4 \\
3 & 18.8 & 15.7 & 24.5 & 21.4 \\
3 average & & & & 22.3 \\
\hline
\end{tabular}

${ }^{a}$ Calculated based on values lower than the detection limit

$0.5 \%$ ethylenediaminetetraacetic acid (EDTA) solution reduced the residual radioactivity levels to $1 / 3$ rd.

As shown in Table 10.2, the residual radioactive cesium level reached a plateau after three washes (Watabe et al. 2013). A similar trend was also observed with Pacific cod using three washing volume (body weight $=473$ and $744 \mathrm{~g}$, body length $=35.0$ and $40.0 \mathrm{~cm}$; Table 10.2); therefore, the most efficient washing volume may be independent of the fish species.

We also evaluated the effects of the size of meat samples on the washing efficiency. Nibe croaker (body weight $=241-368 \mathrm{~g}$ and body length $=27.8-30.0 \mathrm{~cm}$ ) meat was cut into small pieces and washed with three volumes of $0.1 \%(\mathrm{w} / \mathrm{v}) \mathrm{NaCl}$ solution (Watabe et al. 2013). The pieces were stirred in the salt solution at $15^{\circ} \mathrm{C}$ for 5 min and used as group A samples. Another portion was homogenized using a Waring blender (Ace AM-8, Nissei, Tokyo, Japan) at 8,000 rpm for $5 \mathrm{~min}$ and used as group B samples. After centrifugation of both groups at $2,500 \times \mathrm{g}$ for $10 \mathrm{~min}$, the pellets were subjected to further washing procedures in $0.1 \% \mathrm{NaCl}$ solution under the same conditions and used to monitor the radioactivity levels. The samples from groups A and B that received " $n$ " washes were defined as A-n and B-n, respectively. Group B samples that were homogenized using a Waring blender showed cesium 
Table 10.3 Effects of homogenization on the residual radiocesium level in nibe muscle (cited from Watabe et al. 2013)

\begin{tabular}{lllll}
\hline Sample & ${ }^{134} \mathrm{Cs}(\mathrm{Bq} / \mathrm{kg})$ & ${ }^{137} \mathrm{Cs}(\mathrm{Bq} / \mathrm{kg})$ & Total Cs $(\mathrm{Bq} / \mathrm{kg})$ & Residual Cs $(\%)$ \\
\hline Meat & 151 & 183 & 334 & 100 \\
A-1 & 32.3 & 44.3 & 76.6 & 23.8 \\
A-2 & 28.6 & 40.8 & 69.4 & 21.7 \\
A-3 & 26.1 & 38.8 & 64.9 & 20.3 \\
B-1 & 38.5 & 47.3 & 85.8 & 27.1 \\
B-2 & $16.8^{\mathrm{a}}$ & 24.8 & 41.6 & 14.4 \\
B-3 & $5.8^{\mathrm{a}}$ & 12.3 & 18.1 & 5.9 \\
\hline
\end{tabular}

${ }^{a}$ Calculated based on values lower than the detection limit

elimination with a high efficiency (a final residual radioactivity of approximately $5 \%$; Table 10.3), probably because of the larger surface area of the homogenized meat. This may be an effective approach for eliminating radioactive Cs. However, extensive washing of small pieces of meat may also remove the flavor attributable to amino acids, nucleotides, and other small compounds present in surimi, thereby yielding a tasteless product. Thus, appropriate conditions should be determined for a balance between risk reduction and food quality.

Washing fish muscle contaminated with radioactive cesium may be a very effective approach for the production of surimi-based products. This method may also be applicable to the production of other processed seafood such as boiled, dried, or seasoned products. These trials are currently in progress in our research.

Acknowledgments We sincerely thank Ms. Matsuoka, Dr. Nakaya, Dr. Tanoi, and Dr. Nakanishi at the University of Tokyo and Mr. Satoh and Mr. Nemoto at the Fukushima Prefectural Experimental Fisheries Research Station for their cooperation. This study was partly supported by a Grant-in-Aid from the Ministry of Education, Science, Technology, and Sports of Japan for the Tohoku Marine Science Program.

Open Access This article is distributed under the terms of the Creative Commons Attribution Noncommercial License which permits any noncommercial use, distribution, and reproduction in any medium, provided the original author(s) and source are credited.

\section{References}

Fishery Research Agency (2012) Report on research program for the effect of radioactive materials. http://www.jfa.maff.go.jp/j/sigen/housyaseibussitutyousakekka/pdf/h23report_final_1.pdf

Madigan DJ, Zofia Baumannb Z, Fisher NS (2012) Pacific bluefin tuna transport Fukushimaderived radionuclides from Japan to California. Proc Natl Acad Sci USA 109:9483-9486

Saiki S, Okano S, Mori T (1955) Studies on the radioactive material in the radiologically contaminated fishes caught at the Pacific Ocean in 1954. Bull Jpn Soc Sci Fish 20:902-906

Watabe S, Matasuoka Y, Nakaya M, Ushio H, Nemoto Y, Sato M, Tanoi K, Nakanishi T (2013) Removal of radiocesium accumulated in fish muscle by washing aimed for production of surimi-based products. Radioisotopes 62:31-38 